\title{
Inhibition of acoustic startle using different mechanoreceptive channels
}

\author{
B. D. HILL and TERRY D. BLUMENTHAL \\ Wake Forest University, Winston-Salem, North Carolina
}

\begin{abstract}
In this experiment, we investigated the impact of vibrotactile prepulse frequency and intensity on the acoustically elicited startle response in humans. Mechanoreceptive channels differing in their sensitivity to transient stimulation have been identified in the skin. The Pacinian channel is optimally sensitive to vibrations at approximately $300 \mathrm{~Hz}$ and is specialized for the detection of stimulus transients, whereas the non-Pacinian I and III channels are optimally sensitive to vibrations at approximately $30 \mathrm{~Hz}$. Vibrotactile prepulses with frequencies of 30 and $300 \mathrm{~Hz}$ and intensities of 95 and $130 \mathrm{mV}$ were presented for $50 \mathrm{msec}$ to the dominant hand of college students $(N=31)$, followed on some trials by a 95-dB broadband acoustic startle stimulus. The $300-\mathrm{Hz}$ prepulses resulted in significantly more pronounced inhibition of startle magnitude, amplitude, and probability, whereas only the 30-Hz prepulses significantly facilitated blink latency. These results support the idea that the inhibition of acoustic startle is determined more by transient than by sustained aspects of vibrotactile prepulse stimuli. This study also demonstrates that different aspects of the startle response differentially reflect stimulus characteristics of the prepulse.
\end{abstract}

The startle response is a brainstem reflex elicited by a sudden stimulus (Berg \& Balaban, 1999). The response to the startle-eliciting stimulus is modified by the prior presentation of a weaker stimulus, called a prepulse, an effect most often referred to as prepulse inhibition, or PPI (Blumenthal, 1999). Prepulse stimuli effectively modify the startle response when presented $30-500 \mathrm{msec}$ prior to the startle-eliciting stimulus (Graham, 1975, 1992). For the startle-elicited eyeblink response, the observed modification varies from slight reduction to absolute suppression of the eyeblink, depending on a number of variables. However, the inhibitory effect does not depend on either learning or motivation on the part of the participant (Graham, Putnam, \& Leavitt, 1975).

According to Graham (1992), PPI serves to protect the processing of the prepulse from interruption by the startle stimulus. The onset of the prepulse activates two preattentive processes, one of which identifies the stimulus and the other of which inhibits processing of later occurring stimuli until the first stimulus is identified. Greater inhibition of startle has been shown to correlate with more complete processing of the lead stimulus or prepulse (Norris \& Blumenthal, 1996). PPI is the result of the activation of a transient detection system with a narrow window of temporal summation (up to $50 \mathrm{msec}$; Blumenthal, 1995). The distinction between transient and sustained stimulus processing is analogous to the distinction between stimulus detection and stimulus

Portions of this research were submitted by B.D.H. as partial fulfillment of the requirements for a master's degree at Wake Forest University. Correspondence should be addressed to T. D. Blumenthal, Department of Psychology, Wake Forest University, Winston-Salem, NC 27109 (e-mail: blumen@wfu.edu). identification, with these fundamental information processing stages depending on distinct underlying neuronal systems (Blumenthal, 1995; Gersuni et al., 1971). PPI is believed to be due to the activation of rapidly summating neurons that preferentially process transient aspects of a stimulus (change detectors; Blumenthal, 1999; Graham, 1992). This has clearly been shown with acoustic prepulses, and one purpose of the present study was to evaluate the impact of transient system activation by tactile stimuli on PPI of acoustic startle responding. Such an effect would show that stimulus transients across sensory modalities have an impact on PPI, illustrating a general parameter of inhibition of the startle response across sensory modalities.

Tactile stimuli activate mechanoreceptive channels in the skin. Four discrete mechanoreceptive channels for glabrous skin have been proposed (Bolanowski, Gescheider, Verrillo, \& Checkosky, 1988; Gescheider, Bolanowski, \& Hardick, 2001) and have been labeled Pacinian, and non-Pacinian I, II, and III. The Pacinian channel is maximally sensitive at $300 \mathrm{~Hz}$ but can be activated by vibrations as low as $60 \mathrm{~Hz}$ and as high as $500 \mathrm{~Hz}$, given sufficient stimulus intensity (Ochoa \& Torebjork, 1983). The Pacinian channel detects the onset and offset of a stimulus, acting as a transient detection system (Gescheider, Hoffman, Harrison, Travis, \& Bolanowski, 1994). Pacinian corpuscles are pressure-sensitive, encapsulated receptors that are rapidly adapting and have a large receptive field (Zelena \& Jirmanova, 1988). Thus, the receptor cannot function as a sustained detector, because the discharge of action potentials depends on the onset or offset of the mechanical event caused by the stimulus.

The non-Pacinian (NP) channels are composed of three distinct nerve fibers: rapidly adapting fibers (NP I), 
slowly adapting type I fibers (NP II), and slowly adapting type II fibers (NP III). These channels function largely as sustained identification systems, although aspects of transient detection are also present (Gescheider et al., 1994). All three channels broadly overlap in frequency sensitivity, but each channel is significantly more sensitive than the others for frequencies in very specific ranges. NP I is primarily served by Meissner corpuscle receptors, which are optimally sensitive at $30-50 \mathrm{~Hz}$ (Gescheider et al., 2001) but can detect vibrations in the range of $10-60 \mathrm{~Hz}$ (Mountcastle, Lamotte, \& Carli, 1972). Like the Pacinian corpuscles, these are rapidly adapting, but they have small receptive fields. These receptors fire at the onset of stimuli, but they have a higher activation threshold than do Pacinian corpuscles at high frequencies (Gescheider et al., 2001). The NP II channel is optimally sensitive at $250 \mathrm{~Hz}$ (Gescheider et al., 2001) and is not affected by stimulus duration since it is incapable of temporal summation (Gescheider, Berryhill, Verrillo, \& Bolanowski, 1999). The NP III channel is specialized for the detection of low-frequency vibrations. This channel is most sensitive at frequencies from 20 to $40 \mathrm{~Hz}$ (Bolanowski et al., 1988). It is believed to receive input primarily from Merkel cell neurite complexes, also known as Merkel tactile disks.

In summary, Gescheider et al. (2001) reported that the NP I channel was optimally sensitive at $30-50 \mathrm{~Hz}$, the NP II channel at $250 \mathrm{~Hz}$, the NP III channel at 20 to $40 \mathrm{~Hz}$, and the Pacinian channel at $300 \mathrm{~Hz}$. At frequencies above $200 \mathrm{~Hz}$, the Pacinian channel is $20 \mathrm{~dB}$ (re $1 \mathrm{mi}-$ crometer of displacement) more sensitive than the NP II channel (Gescheider, Bolanowski, \& Verrillo, 2004). The Pacinian channel is purely a transient detection system, whereas the NP channels mix elements of transient and sustained systems.

Previous research has found conflicting results about the degree of startle inhibition produced by vibrotactile prepulses at different frequencies. Lovelace and Blumenthal (1991) presented participants with both $50-\mathrm{Hz}$ and $250-\mathrm{Hz}$ prepulses. They did not find a main effect of prepulse frequency for startle response probability or amplitude but did report that the $50-\mathrm{Hz}$ prepulse facilitated startle response latency. However, the use of prepulses at 50 and $250 \mathrm{~Hz}$ resulted in a comparison of the inhibitory effect of the NP I channel with the NP II channel, both of which are mixed transient/sustained channels.

Hill and Blumenthal (2002) reported that a $300-\mathrm{Hz}$ prepulse resulted in significantly more inhibition of the startle response than did a $30-\mathrm{Hz}$ prepulse. The $300-\mathrm{Hz}$ prepulse activated the Pacinian channel, a purely transient system. Hill and Blumenthal also reported that both prepulses significantly facilitated blink latency, indicating that the $30-\mathrm{Hz}$ prepulses were being processed, but they simply did not produce significant PPI. These results were interpreted as supporting a transient-based model of startle inhibition across sensory modalities. The main difference between the studies of Lovelace and Blumenthal (1991) and Hill and Blumenthal was the separate activation of the Pacinian and NP channels in the latter study.
However, a potential confound may have occurred in the Hill and Blumenthal (2002) study. Their methodology called for prepulse intensities to be set individually by each participant (method of adjustment). Prior to testing, participants were presented with the $300-\mathrm{Hz}$ vibrotactile prepulse with an intensity (input to the vibrator) of $130 \mathrm{mV}$. The $30-\mathrm{Hz}$ prepulse was then presented, and the participant guided the researcher in adjusting the voltage, and thus the intensity, of the $30-\mathrm{Hz}$ prepulse until the participant responded that both the 30- and the $300-\mathrm{Hz}$ prepulses had equal perceptual intensities. Since equality of perceived stimulus intensity was the goal, the actual voltages of the prepulses varied between participants. More problematic, however, was the fact that the mean voltage setting of the $30-\mathrm{Hz}$ prepulse was $95 \mathrm{mV}$. This is significantly lower than the $130 \mathrm{mV}$ at which the $300-\mathrm{Hz}$ prepulse was set during the experiment, raising the question of whether the observed effect was due to absolute stimulus intensity instead of a true differential activation of mechanoreceptive channels based on prepulse frequency.

The objective of the present experiment was to compare the prepulse effect of a purely transient system with that of a mixed transient/sustained system at two different intensities. We hypothesized that a $300-\mathrm{Hz}$ prepulse would inhibit the startle response to a significantly greater degree than would a $30-\mathrm{Hz}$ prepulse at both intensities. As was previously mentioned, PPI is believed to operate through the activation of a transient detection system (Blumenthal \& Berg, 1986; Graham, 1975, 1992). The Pacinian channel, a transient system, is optimally sensitive at $300 \mathrm{~Hz}$. At this frequency, it is much more sensitive than the NP II channel (Gescheider et al., 2004). Furthermore, a $30-\mathrm{Hz}$ prepulse would fall in the optimal sensitivity range of both the NP I and NP III channels. The NP I channel is a mixed transient/sustained system, whereas the NP III channel is a purely sustained system. If a prepulse activating the Pacinian channel resulted in greater PPI than a prepulse that activated the NP channels, it would support the theory that the transient detection of stimuli is a fundamental component of PPI.

\section{METHOD}

\section{Participants}

The participants were 31 male undergraduate college students between 18 and 22 years of age $(M=19.6)$. All were right-handed, as indicated by their handedness inventory scores (Dorthe, Blumenthal, Jason, \& Lantz, 1995), since Lovelace and Blumenthal (1991) showed that tactile prepulse inhibition of startle is less effective in left-handers than in right-handers when the prepulse is applied to the dominant hand. Females were not included due to the fluctuation in tactile sensitivity that occurs throughout the menstrual cycle (Gescheider, Verrillo, McCann, \& Aldrich, 1984). All participants received credit in an introductory psychology course.

\section{Stimuli}

The stimulus used to elicit the startle response was a $95-\mathrm{dB}$ (SPL) broadband noise with a duration of $50 \mathrm{msec}$ and a rise/fall time of less than $1 \mathrm{msec}$. Four vibrotactile prepulse conditions were used: a $30-\mathrm{Hz}$ condition at either 95 or $130 \mathrm{mV}$ and a $300-\mathrm{Hz}$ con- 
dition at either 95 or $130 \mathrm{mV}$. The voltage was measured at the input to the vibrotactile stimulator. An increase in voltage had the direct effect of increasing vibrator movement amplitude or contactor excursion height. All prepulses had a duration of $50 \mathrm{msec}$ and a rise/fall time of $5 \mathrm{msec}$ and were presented at a lead interval (onsetto-onset) of $120 \mathrm{msec}$.

\section{Apparatus}

Two Coulbourn S81-06 precision signal generators created the sinusoidal tones that were used as prepulses. The rise/fall times of each prepulse stimulus were set using individual Coulbourn S84-04 selectable envelope-shaped rise/fall gates. A Ling 203B shaker was used to produce the vibrotactile prepulses. The contact surface was a $3-\mathrm{cm}^{2}$ smooth circular pad. The shaker was positioned beneath a hole in a right-handed wooden desktop in such a way that the $3-\mathrm{cm}^{2}$ contact point was flush with the desktop, with a $1 \mathrm{~mm}$ gap between the vibrator surface and the desktop. The voltage of each prepulse was measured at the onset of testing using a Fluke 8050A series digital multimeter.

A Coulbourn S81-02 noise generator was used to generate the startle stimulus. The 95-dB (SPL) startle stimulus was delivered using Telephonics 49-P headphones. The intensity of the startle stimulus was calibrated daily using a Quest Electronics 215 sound level meter. A CCD 00021 observation camera was positioned on a wooden desk approximately $1.2 \mathrm{~m}$ in front of the participant. This was used to monitor the activity level of the participant in order to prevent the recording of movement artifacts in the EMG data record.

In Vivo Metric Biopotential skin electrodes ( $4 \mathrm{~mm}$ inner diameter; $\mathrm{Ag} / \mathrm{AgCl}$ ) were attached beneath the left eye of each participant and used to record EMG activity from the orbicularis oculi muscle. This information was recorded by a Biopac Systems MP150 EMG amplifier that amplified the signal by a factor of 5,000, and was sampled $(1000 \mathrm{~Hz})$ by an IBM $300 \mathrm{GL}$ microcomputer running AcqKnowledge 3.7 software, which was used to record all data. EMG data were filtered (passband of 28-500 Hz), then rectified and smoothed (10-msec time constant) by the AcqKnowledge program.

\section{Procedure}

The participants were tested individually, with each session lasting approximately $30 \mathrm{~min}$. Each participant signed an informed consent form and filled out both a health questionnaire and a handedness inventory. He then sat in a sound-attenuated room, at a student's desk, with the vibrating mechanism built into the desktop. The participant was instructed to place the thenar eminence of his right hand (this area was pointed out to the participant) on the contactor surface of the vibrator. Next, rubbing alcohol was used to clean the skin surface beneath the left eye and on the left temple. A recording electrode was placed directly below the pupil, with a second electrode placed lateral to the first, with the centers of the electrodes separated by about $13 \mathrm{~mm}$. A third electrode was placed on the left temple to act as a ground.

The participant was told that he would occasionally hear a loud noise through the headphones and would also occasionally feel a vibration on his right hand. The participant was instructed to keep the thenar eminence of his right hand in contact with the contactor surface at all times during the experiment. The participant was then instructed to look straight ahead during the experiment, to not move around excessively, to not fall asleep during the experiment, and to not close his eyes except to blink.

A randomized block matrix with five stimulus conditions was used to determine the order of stimulus presentation. The starting trial block was alternated between participants. The control condition consisted of the presentation of the startle stimulus only. The prepulse conditions involved either a $30-$ or a $300-\mathrm{Hz}$ vibration at an intensity (to the vibrator) of either 95 or $130 \mathrm{mV}$. Trials were presented from 10 to $20 \mathrm{sec}$ apart $(M=15)$. Prior to the presentation of the prepulse conditions, each participant was initially presented with four habituation trials in which only the startle stimulus was presented. The prepulse and control conditions were presented six times each, and the habituation condition, consisting of 4 trials, was presented once, for a total of 34 trials per participant.

\section{Scoring Protocol}

Trials were rejected if excessive noise or any movement artifact was seen in the EMG data within $25 \mathrm{msec}$ of the onset of the startle stimulus. A blink response onset was scored if the integrated EMG showed an increase to twice the prestimulus baseline in a window of 20-120 msec after the onset of the startle stimulus (in fact, all response onset latencies were from 28 to $87 \mathrm{msec}$ ). This point provided measures of response onset latency (time from startle stimulus onset to response onset) and response probability (ratio of trials on which a response onset was detected, compared with trials on which a response onset could have been detected). Response magnitude was taken as the peak EMG within a scoring window of $20-150 \mathrm{msec}$ after the onset of the startle stimulus, with a value of zero for trials with no response. Response amplitude was the voltage of peak EMG within the scoring window of 20-150 msec for all trials on which a nonzero response was detected. A failure to respond was recorded as zero for response magnitude and probability, and the trial was labeled "missing" for response amplitude and onset latency. Although response magnitude, amplitude, probability, and onset latency are reported, we emphasize that these measures are not independent of each other. For example, response magnitude is calculated from trials that contribute to response amplitude (when a response is recorded) and response probability (zero magnitude when a response is not recorded). Also, response onset latency and amplitude cannot be calculated on trials without a response onset, so these measures are only valid on trials on which response probability is 1 .

To examine the PPI of response magnitude and amplitude, the difference between responding on prepulse and control trials was divided by responding on control trials $[(\mathrm{PP}-\mathrm{CT}) / \mathrm{CT}]$ (Blumenthal, Elden, \& Flaten, 2004). To examine the PPI of response probability and latency, the difference between responding on prepulse and control trials was calculated.

Due to the fact that zero is not an acceptable value for response amplitude and latency, there were empty cells in the analysis of variance (ANOVA) for these two measures, resulting in exclusion of some participants from these analyses. For this reason, response amplitude and latency analyses were based on 21 of the 31 participants, with all of the data for a participant being excluded from the analysis if he failed to respond to at least one startle stimulus in any one of the five conditions. In fact, the 10 participants for whom the data were excluded responded in at least one trial of the control (no prepulse) condition, but the prepulse caused complete inhibition of startle for 1 participant in the $30-\mathrm{Hz} / 95-\mathrm{mV}$ condition, for 3 participants in the $30-\mathrm{Hz} / 130-\mathrm{mV}$ condition, for 8 participants in the $300-\mathrm{Hz} / 95-\mathrm{mV}$ condition, and for 4 participants in the $300-\mathrm{Hz} /$ $130-\mathrm{mV}$ condition. Six participants lacked responses in two stimulus conditions, and 4 lacked responses in one stimulus condition.

\section{RESULTS}

Mean response levels for each of the four dependent measures in each stimulus condition are presented in Table 1 . The existence of PPI was identified by inspection of the $95 \%$ confidence intervals (CI) for the PPI calculation for each response measure. If this CI included zero, PPI was not present at the $p<.05$ level. Presentation of vibrotactile prepulses caused inhibition of startle response probability in all four prepulse conditions $(p<$ .05 ; see Figure 1). Response magnitude was inhibited in 
Table 1

Mean Response Levels for Each Dependent Measure in Each Stimulus Condition

\begin{tabular}{|c|c|c|c|c|c|c|c|c|}
\hline \multirow[b]{2}{*}{ Stimulus Condition } & \multicolumn{2}{|c|}{$\begin{array}{c}\text { Response } \\
\text { Magnitude* } \\
\text { (in } \mathrm{mV} \text { ) }\end{array}$} & \multicolumn{2}{|c|}{$\begin{array}{c}\text { Response } \\
\text { Probability* }\end{array}$} & \multicolumn{2}{|c|}{$\begin{array}{l}\text { Response } \\
\text { Amplitude** } \\
(\text { in } \mathrm{mV})\end{array}$} & \multicolumn{2}{|c|}{$\begin{array}{l}\text { Response } \\
\text { Latency** }^{* *} \\
\text { (in msec) }\end{array}$} \\
\hline & $M$ & $S D$ & $M$ & $S D$ & $M$ & $S D$ & $M$ & $S D$ \\
\hline Control (no prepulse) & 57.87 & 12.87 & .946 & .027 & 70.60 & 18.28 & 47.22 & 0.99 \\
\hline $30-\mathrm{Hz}$ prepulse at $95 \mathrm{mV}$ & 34.76 & 7.63 & .702 & .058 & 55.69 & 11.70 & 43.14 & 2.04 \\
\hline $30-\mathrm{Hz}$ prepulse at $130 \mathrm{mV}$ & 34.97 & 9.87 & .682 & .062 & 57.71 & 13.20 & 40.93 & 1.83 \\
\hline $300-\mathrm{Hz}$ prepulse at $95 \mathrm{mV}$ & 20.09 & 5.27 & .532 & .073 & 37.17 & 9.36 & 47.64 & 2.98 \\
\hline $300-\mathrm{Hz}$ prepulse at $130 \mathrm{mV}$ & 19.18 & 5.83 & .527 & .064 & 35.23 & 7.02 & 50.38 & 2.48 \\
\hline
\end{tabular}

Note $-{ }^{*} N=31 .{ }^{* *} N=21$ of 31 participants, due to one or more empty cells for 10 participants.

all conditions $(p<.05)$ except the $30-\mathrm{Hz} / 95-\mathrm{mV}$ condition $(p=.065$; see Figure 2$)$. For the subset of 21 participants who produced at least one response per stimulus condition, response amplitude was inhibited only by $300-\mathrm{Hz}$ prepulses $(p<.05)$ and not by $30-\mathrm{Hz}$ prepulses (see Figure 3 ). Response onset latency was significantly facilitated by $30-\mathrm{Hz}$ prepulses at both stimulus intensities $(p<.05)$, but $300-\mathrm{Hz}$ prepulses had no effect on response onset latency (see Figure 4). ${ }^{1}$

To evaluate the relative effectiveness of the different prepulses, PPI of response magnitude, amplitude, probability, and latency was submitted to a $2 \times 2$ repeated measures ANOVA, with prepulse frequency (30 and $300 \mathrm{~Hz})$ and prepulse intensity $(95$ and $130 \mathrm{mV}$ ) as factors. A significant main effect of prepulse frequency was found for inhibition of response magnitude, amplitude, and probability $[F(1,30)=22.99, p<.001 ; F(1,20)=$ $17.33, p<.001$; and $F(1,30)=20.24, p<.001$, respectively]. For all three measures, more inhibition was caused by $300-\mathrm{Hz}$ prepulses than by $30-\mathrm{Hz}$ prepulses (see Figures 1, 2, and 3). Neither the main effect of pre- pulse intensity nor the interaction between prepulse frequency and intensity reached significance for any of these measures. For the main effect of prepulse intensity, the $F$ values were less than 1.50 , with the lowest $p$ value being .25; for the interaction, the $F$ values were less than 0.50 , with the lowest $p$ value being .48 .

Prepulse modification of response onset latency also showed a significant prepulse frequency effect $[F(1,20)=$ $14.35, p<.001$, with latency facilitation caused by $30-\mathrm{Hz}$ prepulses, but no significant change caused by $300-\mathrm{Hz}$ prepulses (see Figure 4). The main effect of prepulse intensity was not significant $(F=0.05)$, although the interaction between prepulse frequency and intensity approached significance for response onset latency $[F(1,20)=3.98$, $p=.06]$.

\section{DISCUSSION}

This study replicated the finding of acoustic startle inhibition by a tactile prepulse (first reported by Blumenthal \& Gescheider, 1987) and the finding of Hill and

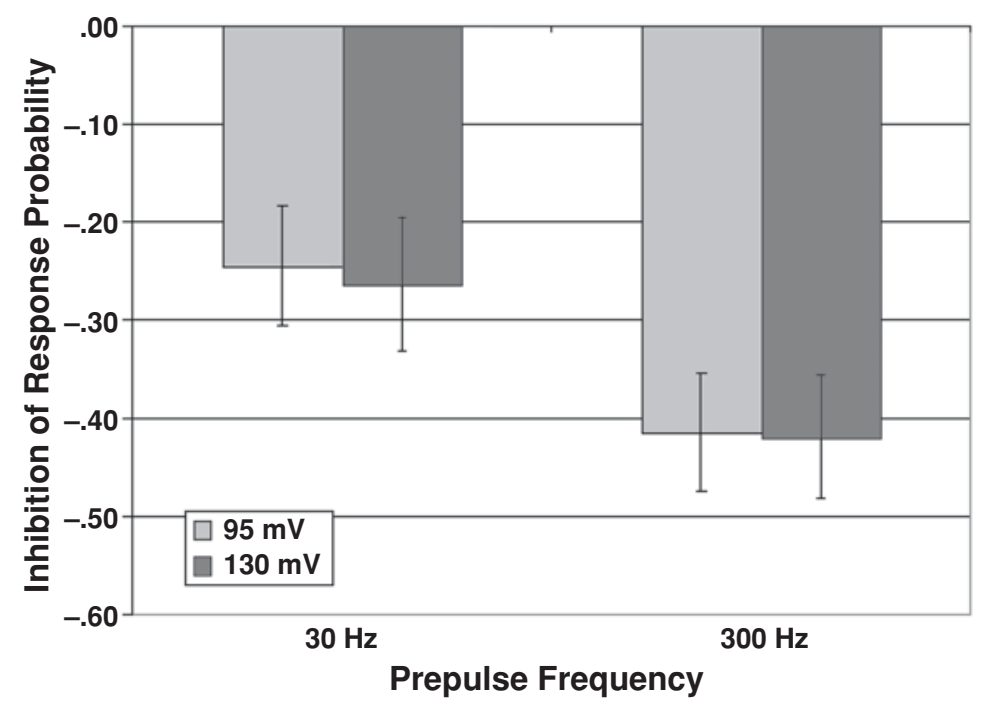

Figure 1. Prepulse inhibition of response probability (proportion of difference from control). Error bars represent one standard error of the mean. 


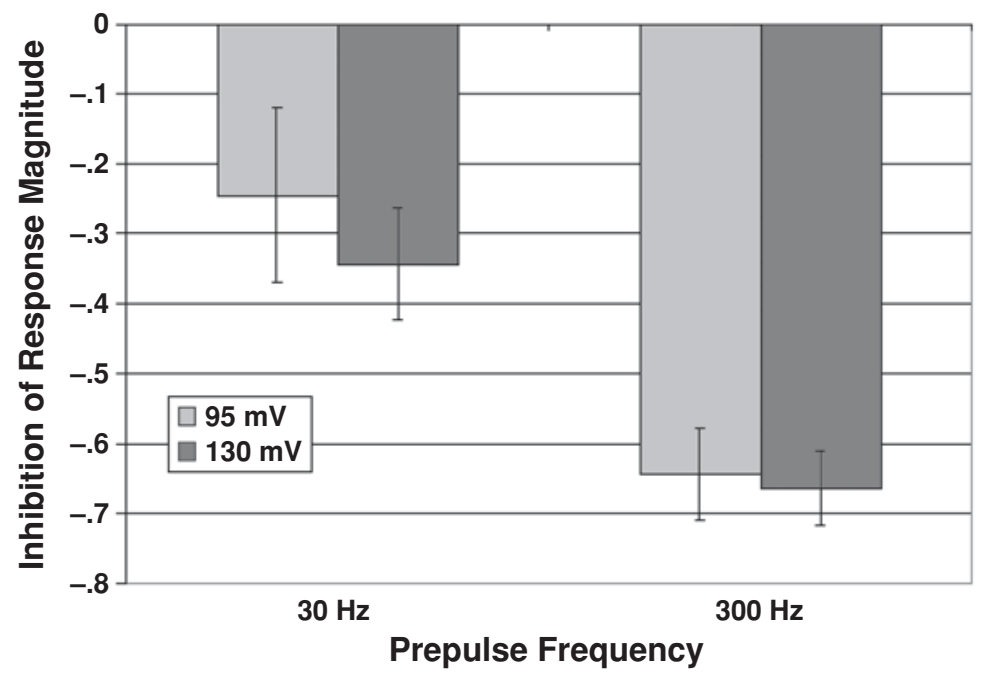

Figure 2. Prepulse inhibition of response magnitude (proportion of difference from control). Error bars represent one standard error of the mean.

Blumenthal (2002) of more pronounced inhibition caused by a $300-\mathrm{Hz}$ vibrotactile prepulse than by a $30-$ $\mathrm{Hz}$ vibrotactile prepulse. The results of Hill and Blumenthal and the present study indicate that a $30-\mathrm{Hz}$ prepulse at $95 \mathrm{mV}$ does not cause significant inhibition of either response magnitude or amplitude, whereas significant PPI is caused by $300-\mathrm{Hz}$ prepulses at $130 \mathrm{mV}$, even though these two prepulses feel subjectively the same at those intensities. The present study found that this highfrequency advantage was still present when the intensity of the $30-\mathrm{Hz}$ prepulse was increased to $130 \mathrm{mV}$ (which amounted to an increase of approximately $3 \mathrm{~dB}$ relative to 1 micrometer of displacement) or when the intensity of the $300-\mathrm{Hz}$ prepulse was decreased to $95 \mathrm{mV}$ (which amounted to a decrease of approximately $3 \mathrm{~dB}$ relative to 1 micrometer of displacement). This clearly shows that high-frequency vibrotactile prepulses are more effective as inhibitors of startle than are low-frequency vibrotactile prepulses.

However, blink onset latency was significantly facilitated by the $30-\mathrm{Hz}$ prepulse at both stimulus intensities, but not by the $300-\mathrm{Hz}$ prepulse at either stimulus inten-



Figure 3. Prepulse inhibition of response amplitude (proportion of difference from control). Error bars represent one standard error of the mean. 


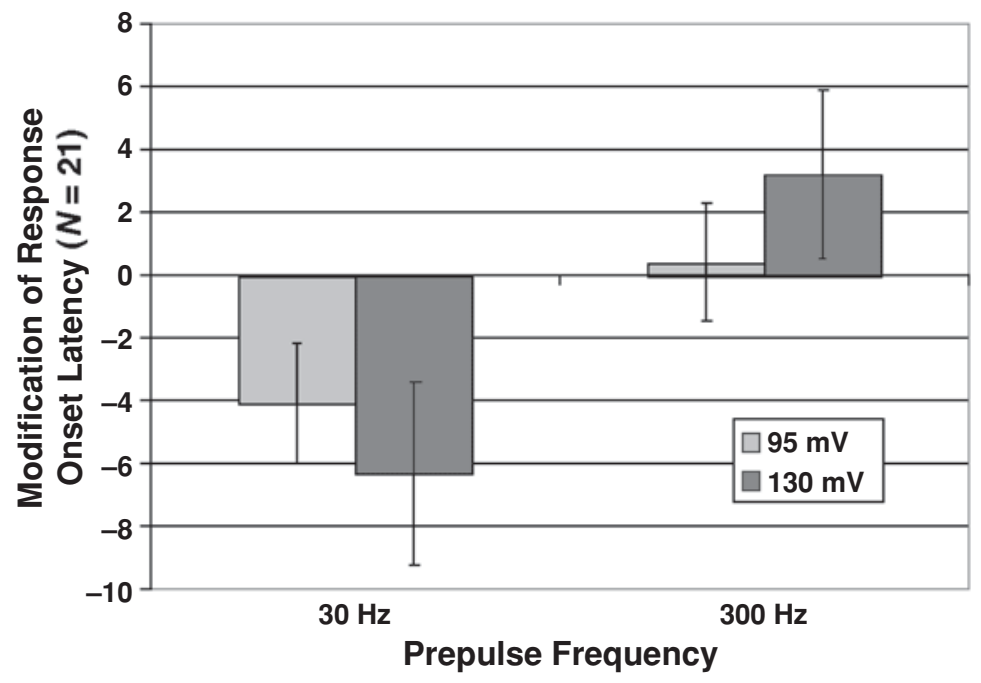

Figure 4. Prepulse modification of response onset latency (proportion of difference from control in milliseconds). Error bars represent one standard error of the mean.

sity. The amount of facilitation produced by the $30-\mathrm{Hz}$ prepulses did not differ significantly as a function of stimulus intensity. This result supports previous findings that the concurrent finding of response magnitude inhibition and blink latency modification involve different neural pathways, or that the same pathway differentially affects the neural substrates of such modifications (Blumenthal \& Gescheider, 1987; Graham \& Murray, 1977; Leitner, Powers, Stitt, \& Hoffman, 1981).

The prepulse frequencies used in this study were chosen because of their ability to activate specific mechanoreceptors (Gescheider et al., 2001). A 30-Hz tactile stimulus predominantly activates Meissner corpuscles and Merkel tactile disks, which innervate the NP I and NP III mechanoreceptive channels, respectively. The Meissner corpuscle fires at the onset of tactile stimulus presentation, producing a flutter-like sensation of onset with no offset (Talbot, Darian-Smith, Kornhuber, \& Mountcastle, 1968). Merkel tactile disks are activated as long as the skin is indented. Because of these activation characteristics, the NP I channel functions as a weak transient system, and the NP III channel functions as a sustained identification system. The $30-\mathrm{Hz}$ stimulus, therefore, activated a mixed transient/sustained system. A $300-\mathrm{Hz}$ stimulus presented to glabrous skin predominantly activates Pacinian corpuscles, which are associated with the Pacinian mechanoreceptive channel. The Pacinian corpuscle fires only at the onset and offset of a tactile stimulus, functioning as a transient detection mechanism. The results of the present experiment indicate that the prepulse inhibition system is preferentially activated by sensory stimuli that activate transient systems. Also important is the fact that the $30-\mathrm{Hz}$ prepulse at $130 \mathrm{mV}$ results in less pronounced inhibition than that caused by the $300-\mathrm{Hz}$ prepulse at $95 \mathrm{mV}$. This underscores the fact that the main variable affecting the degree of PPI is the receptor population that is activated by the prepulse, even at different stimulus intensities. This dependence of prepulse inhibition on transient system activation is analogous to Blumenthal's (1995) conclusion regarding acoustic prepulse inhibition of acoustic startle responding. The present study extends those earlier findings to another sensory modality, the vibrotactile channel. Since prepulse inhibition of startle can be accomplished by the presentation of prepulses in any sensory modality, crossmodal PPI studies may be useful in the investigation of transient and sustained processing in a variety of sensory channels. These findings may be useful in both extending the investigation of PPI into other modality combinations and applying PPI to study different receptor channels in the vibrotactile system.

\section{REFERENCES}

Berg, W. K., \& Balaban, M. T. (1999). Startle elicitation: Stimulus parameters, recording techniques, and quantification. In M. E. Dawson, A. M. Schell, \& A. H. Bohmelt (Eds.), Startle modification: Implications for neuroscience, cognitive science, and clinical science (pp. 21-50). New York: Cambridge University Press.

Blumenthal, T. D. (1995). Prepulse inhibition of the startle eyeblink as an indicator of temporal summation. Perception \& Psychophysics, 57, 487-494.

Blumenthal, T. D. (1999). Modification at short lead intervals. In M. E. Dawson, A. M. Schell, \& A. H. Bohmelt (Eds.), Startle modification: Implications for neuroscience, cognitive science, and clinical science (pp. 51-71). New York: Cambridge University Press.

Blumenthal, T. D., \& BerG, W. K. (1986). The startle response as an indicator of temporal summation. Perception \& Psychophysics, 40, 62-68.

Blumenthal, T. D., Elden, A., \& Flaten, M. A. (2004). A comparison of several methods used to quantify prepulse inhibition of eyeblink responding. Psychophysiology, 41, 326-332.

Blumenthal, T. D., \& Gescheider, G. A. (1987). Modification of the acoustic startle reflex by a tactile prepulse: The effects of stimulus onset asynchrony and prepulse intensity. Psychophysiology, 24, 320-327. Bolanowski, S. J., Gescheider, G. A., Verrillo, R. T., \& Check- 
OSKY, C. M. (1988). Four channels mediate the mechanical aspects of touch. Journal of the Acoustical Society of America, 84, 1680-1694.

Dorthe, N. J., Blumenthal, T. D., Jason, D. R., \& Lantz, P. E. (1995). The use of next-of-kin in assessing handedness. Perceptual \& Motor Skills, 81, 203-208.

Gersuni, G. V., Altman, J. A., Maruseva, A. M., Radionova, E. A., Ratnikova, G. A., \& Vartanian, I. A. (1971). Functional classification of neurons in the inferior colliculus of the cat according to their temporal characteristics. In G. V. Gersuni (Ed.), Sensory processes at the neuronal and behavioral levels (pp. 157-180). New York: Academic Press.

Gescheider, G. A., Berryhill, M. E., Verrillo, R. T., \& BolanOWSKI, S. J. (1999). Vibrotactile temporal summation: Probability summation or neural integration? Somatosensory \& Motor Research, 16, 229-242.

Gescheider, G. A., Bolanowski, S. J., \& Hardick, K. R. (2001). The frequency selectivity of information-processing channels in the tactile sensory system. Somatosensory \& Motor Research, 18, 191-201.

Gescheider, G. A., Bolanowski, S. J., \& Verrillo, R. T. (2004). Some characteristics of tactile channels. Behavioural Brain Research, 148, 35-40.

Gescheider, G. A., Hoffman, K. E., Harrison, M. A., Travis, M. L., \& BolanowsKI, S. J. (1994). The effects of masking on vibrotactile temporal summation in the detection of sinusoidal and noise signals. Journal of the Acoustical Society of America, 95, 1006-1016.

Gescheider, G. A., Verrillo, R. T., McCann, J. T., \& Aldrich, E. M (1984). Effects of the menstrual cycle on vibrotactile sensitivity. Perception \& Psychophysics, 36, 586-592.

GraHAM, F. K. (1975). The more or less startling effects of weak prestimulation. Psychophysiology, 12, 238-248.

Graham, F. K. (1992). Attention: The heartbeat, the blink, and the brain. In B. A. Campbell, H. Hayne, \& R. Richardson (Eds.), Attention and information processing in infants and adults: Perspectives from human and animal research (pp. 3-29). Hillsdale, NJ: Erlbaum.

Graham, F. K., \& Murray, G. M. (1977). Discordant effects of weak prestimulation on magnitude and latency of the reflex blink. Physiological Psychology, 5, 108-114.

Graham, F. K., PUTNAM, L. E., \& LeavitT, L. A. (1975). Lead-stimulation effects on human cardiac orienting and blink reflexes. Journal of Experimental Psychology: Human Perception \& Performance, 1, 161169.

Hill, B. D., \& Blumenthal, T. D. (2002). Startle inhibition by vibro- tactile prepulses: Support for transient system involvement in PPI [Abstract]. Psychophysiology, 39(Suppl. 1), S41.

Leitner, D. S., Powers, A. S., Stitt, C., \& Hoffman, H. S. (1981). Midbrain reticular formation involvement in the inhibition of acoustic startle. Physiology \& Behavior, 26, 259-268.

Lovelace, C. T., \& Blumenthal, T. D. (1991). Hand dominance and the modification of the acoustically elicited startle response by a vibrotactile prepulse. Psychobiology, 19, 265-273.

Mountcastle, V. B., Lamotte, R. H., \& Carli, G. (1972). Detection thresholds for stimuli in humans and monkeys: Comparison with threshold events in mechanoreceptive afferent fibers innervating the monkey hand. Journal of Neurophysiology, 35, 122-136.

Norris, C. M., \& Blumenthal, T. D. (1996). A relationship between inhibition of the acoustic startle response and the protection of prepulse processing. Psychobiology, 24, 160-168.

OCHOA, J. [L.], \& TOREBJORK, [H.] E. (1983). Sensations evoked by intraneural microstimulation of single mechanoreceptive units innervating the human hand. Journal of Physiology, 42, 633-654.

Talbot, W. H., Darian-Smith, I., Kornhuber, H. H., \& MountcasTLE, V. B. (1968). The sense of flutter-vibrations: Comparison of the human capacity with response patterns of mechanoreceptive afferents from the monkey hand. Journal of Neurophysiology, 31, 301-334.

Zelena, J., \& Jirmanova, I. (1988). Critical periods in the development of mechanoreceptors. In P. Hnik, T. Soukup, R. Vejsads, \& J. Zelena (Eds.), Mechanoreceptors: Development, structure, and function (pp. 9-16). New York: Plenum.

\section{NOTE}

1. The means in Table 1 are derived by taking the mean across trials within a condition for each person, and then averaging these means, such that the final mean is weighted equally for each participant. The means represented in the figures for response amplitude and magnitude are based on ratios $[(\mathrm{PP}-\mathrm{CT}) / \mathrm{CT}]$, with this ratio calculated in each stimulus condition, and these ratios are then averaged across participants. In this way, the average of the ratios may be less influenced than the means in Table 1 by data from participants with unusually large or small responses in one condition or another.

(Manuscript received September 18, 2003; revision accepted for publication September 20, 2004.) 